\title{
A contraposição entre teoria e prática em produções textuais de livros didáticos
}

Raquel Ribeiro Moreira ${ }^{1}$

\begin{abstract}
Résumé: L'éternelle discussion entre théorie et pratique est utilisée dans ce travail comme façon d'analyse des manières que la production de texte est développée dans les livres didactiques de langue portuguese. À partir du concept de texte en Analyse du Discours, nous aborderons une proposition textuel d'un livre didactique, à fin d'analyser comment se fixent les relations entre la théorie utilisée par lui et ses propositions des textes.
\end{abstract}

Mots-clés: Texte, Théorie vs. Pratique, Livre Didactique.

Resumo: A eterna discussão entre teoria e prática é empregada neste trabalho como arcabouço analítico na observação dos modos como a produção de texto é desenvolvida em materiais didáticos de língua portuguesa. A partir da conceituação de texto para a Análise do Discurso, abordaremos uma proposta textual de um livro didático voltado para o ensino médio, a fim de analisar como se estabelecem as relações de imbricamento entre a teoria empregada pelo material e sua efetivação na proposição textual.

Palavras-chave: Texto - Teoria vs. Prática - Livro Didático.

\section{Introdução}

Dentro de um quadro político educacional de desvalorização dos profissionais e do papel da educação, onde se reproduzem sentidos, se cristalizam conhecimentos e se impõe uma ordem educativa, a postura diante do modo como o conhecimento se produz (da escola e, principalmente, do professor) se faz intensamente necessária, como pulsação de um corpo que tenta fugir da inércia. Contudo, observamos que a clareza e conscientização quanto a essa postura (que afeta as concepções teóricas e as atividade metodológica de ensino) não é suficiente para impedir o esvaziamento teórico que constitui as práticas pedagógicas da escola de hoje, e, prova cabal disso, são os livros didáticos que, muitas vezes, ou apagam a reflexão teórica de seus manuais, ou distorcem-na, desqualificando na prática o que pregaram teoricamente.

Esse distanciamento entre teoria e prática, exaustivamente discutido em textos,

1 Docente da Universidade Tecnológica Federal do Paraná. Doutoranda em Letras na UFRGS. 
congressos, reuniões sobre a prática escolar, ainda não foi eliminado, nem ao menos diminuído, valendo por si a necessidade de se continuar batendo na mesma tecla, na tentativa de desmistificar mitos e verdades absolutas, aspectos dos quais muitas vezes o livro didático se faz porta-voz, uma vez que ele trabalha na evidência da apreensão/transmissão do conhecimento e na atitude dos sujeitos (professor e aluno) frente a essa evidência, ou seja, de que o conhecimento é unívoco, verdadeiro - portanto detendo uma única interpretação -, e devendo ser transmitido pelos professores e assimilado pelos alunos. Neste cenário, o livro didático aparece como um instrumento importante dessa transmissão. Como o lugar da estabilização, que foi legitimado pela escola e pela sociedade, o livro didático define - tanto para professores quanto para alunos - o que e como se deve ensinar/aprender, estabelecendose como o discurso da competência: o livro didático é o lugar do saber definido, pronto, acabado, correto e, dessa forma, fonte última (e às vezes, única) de referência.

Essas características nos chamaram a atenção de tal modo que instigaram nossa pesquisa $^{2}$. Diversos aspectos do livro didático se mostravam importantes para uma análise, como por exemplo, o modo como a leitura é vista enquanto uma prática denotativa de apreensão de informações, ou ainda, a prioridade dada à gramática normativa em detrimento das questões interpretativas e/ou reflexivas, ou mesmo o completo descaso do livro didático pelos usos e variedades linguísticas, sedimentando um trabalho de mascaramento/ocultação através da higienização e unificação da linguagem. No entanto, resolvemos analisar a produção de texto, justamente por acreditarmos que ela destoa (ou deveria destoar) dessa relação de reprodução/fixação desenvolvida pelo livro didático.

A prática de produção textual põe (ou deveria por) em movimento uma intrincada rede de relações de sentidos que, ao serem tramadas e re-tramadas, desnudam ou opacificam posicionamentos e determinações ideológicas, desestabilizam ou ratificam saberes cristalizados, reproduzem ou diferenciam sentidos. E, essa prática de produção de texto, por nós concebida, não pode ser confundida com uma prática de instrumentalização da escrita, com uma composição redacional em que imperam a consistência, a homogeneidade e a criação, e onde os sujeitos, vistos como responsáveis por seu dizer, devem organizar informações/dados conhecidos (estabilizados) de uma forma coerente e com unidade.

Portanto, a produção de texto, por nós vista, em nada se identifica com as características (especialmente de reprodução e normatização) observadas nos livros didáticos. Daí surgiu nossa inquietação: de que forma, então, é tratada a produção de textos nos livros didáticos? Como se trabalham/apresentam as condições de produção dos textos nesses materiais? Será que os livros didáticos conseguem ultrapassar a condição de exercício redacional geralmente destinado à produção de texto na escola? Para tentar observar tais questões, nos propusemos a verificar as relações existentes entre a teoria utilizada para fundamentar o livro didático aqui apresentado e sua prática efetiva de produção veiculada. Deste modo, embasando-nos na Análise do Discurso francesa, abordaremos, neste artigo, o modo de constituição do conceito de texto em AD e, em seguida, refletiremos sobre as concepções teóricas abordadas no material didático selecionado e cotejaremos a uma de suas propostas de texto, analisando as relações de imbricação com o referencial teórico, a constituição da proposta de texto em face da teoria e o modo de transpor esta última para o campo da prática.

2 Este artigo é parte da Dissertação de mestrado: "Produção Textual em Livros Didáticos: um contraponto entre teoria e prática", defendida em 2004, sob orientação da professora doutora Ana Zandwais, pela Universidade Federal do Rio Grande do Sul. 


\section{O texto para a Análise do Discurso}

Distanciando-se do formalismo, que se ocupa mais da organização lingüística interna ao texto, o que interessa à $\mathrm{AD}$ é o modo como o texto organiza sua relação com a discursividade, ou seja, com a exterioridade, mas não uma exterioridade contextual imediata, mas a exterioridade composta pelas condições de produção que estabelecem uma determinação sobre as práticas discursivas. O texto, então, é o todo que organiza os recortes ${ }^{3}$. Mas esse todo não é uma completude, ele tem compromisso com as condições de produção e com a situação discursiva, situação essa que instaura o ideológico no âmbito do discursivo. Por isso, é que dizemos, em Análise de Discurso, que o "texto representa a materialidade lingüística através da qual se tem acesso ao discurso."

$\mathrm{A} \mathrm{AD}$ entende o texto como formulação, momento em que a linguagem se torna fluída, os sentidos se definem, a memória se atualiza e os sujeitos aparecem. Segundo Orlandi "formular é dar corpo aos sentidos" responsável e autor do que diz, esquecendo sua sujeição/interpelação, acreditando-se senhor, do início ao fim, de seu texto. "Sendo atualização da memória discursiva, a formulação se faz materialmente pela colocação do discurso em texto, pela "textualização". Vemos, dessa forma, o texto em sua materialidade (sua forma, suas traços, seus vestígios) dentro de uma historicidade que, ao mesmo tempo que significa, é significada. Portanto, o texto não expressa idéias, concepções de mundo, informações neutras e objetivas, mas ele aponta, dá indícios sobre a forma com que o sujeito constrói/pratica sentidos; ele corporifica o encontro entre o sujeito, o sentido e a história:

É na formulação que a linguagem ganha vida, que a memória se atualiza, que os sentidos se decidem, que o sujeito se (mostra) se esconde (...) Sujeito e sentido constituindo-se aos mesmo tempo têm sua corporalidade articulada no encontro da materialidade da língua com a materialidade da história. Assim entendemos a afirmação de que há um confronto do simbólico com o político. ${ }^{6}$

É devido a isso que o texto, em $\mathrm{AD}$, se apresenta como uma unidade de análise, um lugar de observação/constatação do funcionamento simbólico; se de um lado o texto é uma condição restrita de linearização e organização discursiva, por outro lado, a partir da formulação sob diferentes modos de discursividade, abre-se para uma multiplicação de possibilidades de versões, uma variança de significações que, retomadas, são diferentemente significadas.

Por isso, o texto não é um simples objeto de aplicação ou prática metodológica. Orlandi (2001) salienta que é preciso pensar a função analítica do texto como lugar do analista trabalhar, na organização (imaginária), a ordem (real) do discurso, atingindo os processos, a memória, a ideologia, pela sua forma imaginária atestada no texto. E é isso

\footnotetext{
3 Segundo Orlandi (1983) o recorte é uma unidade discursiva: fragmento correlacionado de linguagem-e-situação. A idéia de recorte remete à noção de polissemia e não à de informação. Os recortes são feitos na (e pela) situação de interlocução, aí compreendido um espaço menos imediato, mas também de interlocução, que é o da ideologia.

4 ORLANDI, Eni. Discurso e Texto: formação e circulação de sentidos. Campinas, Ed. Pontes, 2001.p.11

5 Ibidem. p.11. A noção de textualização é encontrada em Gallo (1994). Para ela, quando o autor preenche os espaços cambiáveis deixados em branco no texto, indicando a hora e o espaço de determinado evento, contextualizando-o e tornando pública sua produção, dá-se a textualização do texto, produzindo o seu fechamento. 6 ORLANDI, Eni P. Discurso e Texto: formação e circulação de sentidos. Campinas, Ed. Pontes, 2001.p.9
} 
que importa em uma análise discursiva, pois se pensa o texto como variação, composto de exteriores, de margens, de lacunaridades e repetições.

Ao se observar o texto em sua materialidade, ou seja, sua forma, suas inscrições, suas 'cicatrizes', observa-se também como a história significa e é significada, como a ideologia se inscreve na língua, e esta naquela, como o simbólico conjuga o político. Ao visualizar a aparente linearidade textual, observa-se o efeito de transparência e homogeneidade lingüística, interessando-nos o afloramento do real contraditório, na sua dispersão e incompletude. O texto se mostra assim, como "lugar de tensão entre o mesmo e o diferente, dispersão do sujeito e do sentido" ". E, é sob este lugar que se pretende fixar o olhar de analista.

Como o texto é um espaço, mas um espaço simbólico, não é fechado em si mesmo: tem relação com o contexto e com os outros textos (...) O sentido é intervalar. Não está em um interlocutor, não está no outro: está no espaço discursivo (intervalo) criado (constituido) pelo/nos dois interlocutores. Assim como não está em um segmento, nem em outro, nem na soma de todos os segmentos que constituem o texto determinado. Está na unidade a partir da qual os segmentos/recortes se organizam. ${ }^{8}$

É nesse "centro comum", onde interagem autor e leitor - apesar da escrita e leitura serem momentos distintos - que se constitui o texto. Este texto pode ser concebido como um objeto teórico e um objeto empírico. De acordo com Courtine ${ }^{9}$ essa distinção entre objeto teórico (ou de conhecimento) e objeto empírico (ou real, concreto) provém dos trabalhos de Althusser ${ }^{10}$ que situa a contradição constitutiva de todo objeto científico, ou seja, o objeto científico reveste a forma de uma relação contraditória entre objeto real e objeto do conhecimento. Desse modo, enquanto objeto teórico, o texto é aberto, onde trabalham a dispersão do sujeito e dos sentidos, portanto, dotado de incompletude. Já, enquanto objeto empírico, de superfície lingüística, o texto pode se dar como uma "obra acabada", um produto que tem seu desenvolvimento progressivo e linear.

Enquanto algumas teorias lingüísticas tratam do texto nesta segunda opção, a AD observa justamente a incompletude e a dispersão na análise dos textos - mesmo enquanto objeto empírico; isso porque a $\mathrm{AD}$ dimensiona o texto sob suas condições de produção, reinstaurando a multiplicidade própria da constituição de qualquer texto. É nesse sentido, que Courtine afirma que a "materialização, sob a forma de procedimentos determinados, de um corpo de proposições teóricas, visa o discurso como ‘objeto de conhecimento', tendo prioridade sobre o discurso como objeto empírico concreto ou 'objeto real'."11 É essa a condição a partir da qual, segundo o autor, a expressão "objeto da Análise do Discurso", ou mesmo, "o discurso como objeto" pode ser usada.

É, desse modo portanto que, ao observarmos as condições de produção, é que percebemos que o texto tem relação com outros textos, além da situação imediata e de memória que lhe pertencem e à qual este texto tem pertencimento; e isto não lhe permite conceber um caráter de completude, acabamento, mas pelo contrário, o texto é visto

\footnotetext{
7 Ibidem. p. 12

8 ORLANDI, Eni P. A linguagem e seu funcionamento: as formas do discurso. Campinas, Ed. Pontes, 1983. p.160

9 COURTINE, Jean-Jacques. Quelques problèmes théoriques et métthodologiques en analyse du Discours; à propos du discourse communiste adressé aux chrétiens. Langages, (62): 9-127. Paris, juin, 1981.

10 Courtine cita, especialmente, o texto de Althusser: "La philosophie comme arme de la révolution", publicado em 1968 na revista La Pensée $-\mathrm{n}^{\circ} 138$.

11 Ibidem. p. 11
} 
como tensão, um espaço de limites difusos e sobrepostos, do qual resulta a multiplicidade possível de sentidos.

Concebendo o texto como um espaço simbólico, em que seu fechamento não passa de um efeito, pois ele "sempre" estabelece relações com o contexto sócio-histórico, com outros textos e outros discursos, com o já-dito, esquecido e retomado; AD interessa-se pelo modo como a exterioridade se organiza no texto de forma a produzir nele um efeito de fechamento - essencial para o trabalho do sujeito: a ilusão de homogeneidade.

É nesse sentido, de um texto heterogêneo que se "mostra" homogêneo que, Indursky 12 descreve uma série de fatores que fazem parte da constituição do texto:

- As relações contextuais - que remetem o texto para o contexto socioeconômico, político, cultural, e histórico em que é produzido, determinando as condições de sua produção.

- As relações textuais - que relacionam um texto com outros textos, a intertextualidade ${ }^{13}$, que é deslocada para não somente apontar o(s) discurso(s) de origem, mas que aponta também os discursos que fazem parte da mesma matriz de sentido em que o texto é produzido, tanto os discursos existentes, possíveis, quanto os imaginados.

- As relações interdiscursivas - que aproximam o texto de outros discursos, remetendo-o a redes de formulações tais que já não é possível distinguir o que foi produzido no texto e o que é proveniente do interdiscurso. É o que dissemos acima, ou seja, trabalha-se com o já-dito, esquecido, apagado, retomado, re-significado, modificado.

É devido a esses fatores que não podemos afirmar que, embora indispensável como efeito, o texto é um espaço restrito entre a materialidade lingüística e aquilo que lhe circunda. A exterioridade, entendida como discursividade, é constitutiva e presente no texto, mesmo não sendo visível ou reconhecida de imediato. Então, o texto não é uma instância homogênea, mas é encarado como tal por seu sujeito-autor, isto é, pelo sujeito que, interpelado ideologicamente e identificado com uma posição-sujeito inscrita em uma FD, produz seu texto de um determinado lugar social. Segundo Indursky:

em seu trabalho de escritura, o sujeito-autor mobiliza vários e diversificados recortes textuais relacionados a diferentes redes discursivas e diferentes subjetividades. Tal fazer o conduz a estabelecer uma trama entre diferentes recortes discursivos, provenientes de diferentes textos afetados por diversas Formações Discursivas e diferentes posições-sujeito. ${ }^{14}$

É desse trabalho do sujeito-autor de mobilizador e organizador que cria-se o efeito de homogeneidade, de unidade de sentido do texto, pois o sujeito faz de um emaranhado de discursos e textos uma tessitura com, ilusoriamente, "começo, meio e fim". Contudo, ao mobilizar e organizar discursos e textos dispersos e diversos, o sujeito-autor produz signifi-

12 INDURSKY, Freda. Da heterogeneidade do discurso à heterogeneidade do texto e suas implicações no processo de leitura. In: ERNEST-PEREUS, A. \& FUNCK, S. (orgs.) A leitura e a escrita como práticas discursivas. São Paulo, Educat, 2001. p.29

13 Indursky diz entender a intertextualidade como a retomada/releitura que um texto produz sobre outro texto, dele apropriando-se para transformá-lo e/ou assimilá-lo. Esta, porém difere do interdiscurso, já que esse pode ser entendido como a memória do dizer e remete a redes discursivas de onde não se pode identificar com precisão a origem de um texto, visto que o discurso está disperso em uma profusão descontínua e dispersa de textos, relacionando-os com FD diversas, e mobilizando posições-sujeitos também diversas. A intertextualidade e o interdiscurso são, na visão da autora, duas formas distintas de relação com a exterioridade que participam da constituição do texto.

14 Ibidem. p.31 
cados; na retomada do mesmo, ao diferente, o sujeito produz sentidos. E, por isso, dizemos que ele produz a textualização de recortes vindos de outros lugares (sociais, ideológicos, discursivos) heterogêneos que, ao serem inseridos em seu texto, reconstextualizam-se, se naturalizam, pois ao serem esquecidas/apagadas as marcas de sua procedência, geram o que Indursky ${ }^{15}$ chama de efeito de textualidade, e com ele o de homogeneização do texto. É isto que faz com que o sujeito se coloque como responsável pelo que diz, pela constituição de seu texto. Assim, o trabalho de organização e internalização da exterioridade se "apaga", e o sujeito acredita-se como o produtor dos sentidos ali existentes; é preciso, para o processo de constituição do texto, que as alteridades e dispersões sejam alinhadas, linearizadas e formalizadas como singulares e uniformes. O já-dito deve ser esquecido e retomado como novo, surpreendente; o ressoar deve parecer um criar: "A superfície textual precisa parecer perfeitamente plana, lisa, uniforme, enfim, sem asperezas. Só assim a ilusão de homogeneidade se instaura e o efeito-texto ${ }^{16}$ se produz." ${ }^{17}$

Esse efeito-texto aparenta completude, por isso o caráter de, como já foi dito, certeza e unidade de sua construção. Assim como a homogeneidade, a unidade também é simbólica, porém isso é necessário para o trabalho do sujeito de construção do texto, assim, ele acredita estar estabilizando o sentido intencionado, dando consistência ao seu texto. Esses efeitos, de estabilização, consistência e transparência, fazem parte dos esquecimentos em que o sujeito é constituído em seu dizer, com isso, da mesma forma em que ele se historiciza - devido sua inscrição em uma FD - ele historiciza seu texto, constituindo-o de uma rede de outros discursos que retornam e se ressignificam. O trabalho do sujeito-autor é, justamente, o de tornar "simbolicamente" estruturado o espaço discursivo em que ele produz seu texto, é de (ilusão) estabilizar tudo o que é constituído a partir de deslocamentos, derivas e rupturas e, com isso, atribuir os "seus" sentidos, garantindo o fechamento formal e imaginário do texto.

Portanto, como vimos, a AD trabalha em um espaço intervalar entre a constituição histórico-ideológica do texto, numa relação direta entre constituição do sujeito e constituição do discurso e, a ilusão necessária de origem, controle e unidade em que o sujeito-autor se coloca/propõe. Enquanto analistas e sujeitos-autores não fugimos dessa (mais uma) contradição que nos assujeita a conceber no ilusório ponto final, um fim e uma dispersão.

do ponto de vista discursivo, não há ponto final como não há um começo absoluto. Mas na instância do imaginário, em que o sujeito toma forma na história e funciona pela ideologia, ele se realiza em sua função-autor que começa e termina seu texto. De um lado, dispersão do sujeito e do sentido, de outro, unidade do texto e do autor, de um lado incompletude do discurso, de outro, acabamento do texto, onde a linguagem tem imaginariamente dimensões precisas, com recortes, segmentos, tamanhos. ${ }^{18}$

Não pretendemos, neste trabalho de análise de proposta de produções textuais em materiais didáticos, levar o aluno a perceber e trabalhar essa contradição, isto é, levá-lo a perceber a constitutiva incompletude e opacidade dos textos. Entendemos que trabalhar nesse "espaço difuso" é papel do analista do discurso, e que, tampouco a escola é o lugar de

15 Ibidem.p. 31

16 Conforme Gallo (1994) o "efeito-texto" é o efeito de realidade e unidade do enunciado.

17 INDURSKY, Freda. Da heterogeneidade do discurso à heterogeneidade do texto e suas implicações no processo de leitura. In: ERNEST-PEREUS, A. \& FUNCK, S. (orgs.) A leitura e a escrita como práticas discursivas. São Paulo, Educat, 2001. p.32

18 ORLANDI, Eni P. Discurso e Texto: formação e circulação de sentidos. Campinas, Ed. Pontes, 2001.p.114 
“escamotear" todas as ilusões do sujeito, tanto porque elas são necessárias para a formação de sua identidade (quer dizer, para a sua identificação com determinada posição-sujeito dentro de uma FD). Contanto, também não pretendemos reproduzir as metodologias que se pautam em uma objetividade do sujeito-autor, constituindo o texto como um todo original, homogêneo, coerente e unitário. O que pretendemos, ao repensar as propostas de produção textual dos materiais didáticos, é que, a partir de uma outra concepção de língua, uma outra concepção de sujeito - pautados na historicidade e na dispersão dos sentidos, possamos trabalhar o texto reinstalando, sempre, as suas condições de produção. É, a partir de um trabalho do ponto de vista das condições de produção, que se poderá perceber, e levar o aluno a perceber, a relação do texto com a situação imediata e interdiscursiva que o compõe; percebendo assim a relação imbricada do seu texto (aluno) com outros textos.

Quando dissemos que é, a partir da reinstalação das condições de produção que poderemos partir para um trabalho diferenciado de texto, não podemos esquecer, em primeiro lugar, o que entendemos por condições de produção: são todas as determinações histórico-sociais que caracterizam um processo discursivo. Segundo Courtine:

\begin{abstract}
A noção de condições de produção do discurso regra, em AD, a relação da materialidade lingüística de uma seqüência discursiva às condições históricas que determinam as produções; ela funda, assim, os processos de constituição do corpus discursivo (conjunto de seqüências discursivas dominadas por um estado dado, suficientemente homogêneo e estável, das condições de produção de um discurso). ${ }^{19}$
\end{abstract}

São as condições de produção, nessa perspectiva, que fazem a ligação entre o lingüístico, o histórico e o ideológico. Pêcheux (1997:82), afirma que os elementos que fazem parte das condições de produção designam lugares determinados na estrutura de uma formação social, e que esses lugares estão representados nos processos discursivos em que são colocados em jogo. Dessa forma, ao mesmo tempo em que as condições de produção remetem à formação social em que o discurso é produzido, é através das próprias condições de produção que essa(s) formação(ões) social(is) se representam no processo discursivo. As condições de produção do discurso "mostram a conjuntura em que o discurso é produzido, bem como suas contradições ${ }^{20 "}$; é por isso que essa noção se mostra como diferencial e imprescindível na concepção de texto que queremos abordar; a partir de determinadas condições de produção o sujeito pode produzir o seu texto percebendo que ele não é a fonte dos sentidos, ao mesmo tempo em que se coloca no trabalho simbólico e imaginário de representação social.

E, é sob esse viés que olharemos para a proposição de textos em materiais didáticos, observando e considerando as condições de produção numa interdependência da língua, da história, da sociedade e do sujeito; configurando texto como lugar de tensão entre o mesmo e diferente, concebido na dispersão do sujeito,como um espaço simbólico em que faz intervir o trabalho político.

Texto, na perspectiva que adotamos, não pode ser visto como um produto que tem uma origem determinada e um fim pretendido, que deve conter uma progressão e uma sistematização determinada estruturalmente, enfim, não acreditamos em uma concepção de texto como produto, instrumento exercitivo, um objeto de 'habilitação' e 'avaliação' do aluno sobre um determinado conteúdo.

19 COURTINE, Jean-Jacques Op. Cit. p.246

20 Cf. INDURSKY, 1997, p.28 


\section{Conexão Letras}

Ressignificar tal concepção textual, necessitaria de um repensar teórico sobre o que é texto e suas condições de produção, além de desvincularmos o papel central da produção textual de sua organização lingüística interna ou tipológica. È preciso levar em consideração, inapelavelmente, as condições sócio-históricas de produção dos textos, a identificação de possíveis interlocutores que, no domínio de memória do sujeito-autor possam construir significação, e, não confinar o contexto sócio-histórico à mera situação de construção do texto, mas contribuir - no instante do trabalho com o texto - para que o sujeito-aluno tenha acesso às diferentes e divergentes posições que um discurso pode assumir em determinada FD. Dessa maneira, acreditamos, permitir-se ao sujeito-autor reconstituir (de uma forma ilusoriamente homogênea) a situação mediata, circunstancial, lingüística e intertextual necessária para que ele possa construir seu texto (enquanto efeito) como objeto acabado, constituído de uma totalidade com começo, meio e fim. Precisaríamos, enfim, como afirma Orlandi (2001), dentro desta concepção de texto e ensino de produção textual, atestar-lhes:

o modo pelo qual, pela sua função de autor, o sujeito administra a dispersão e a pressão da multiplicidade das possíveis formulações (outras) no mesmo sítio de significação. Jogo intrincado de diferentes formações discursivas, a Unidade resulta de uma construção imaginária que rege a incompletude e a dispersão real dos sujeitos e dos sentidos arregimentados pela força organizadora da ideologia, no funcionamento discursivo das relações de poder que se simbolizam. ${ }^{21}$

Acreditamos que, ao tratarmos o texto como materialidade, constituindo-lhes interlocutores, relativizando o papel da língua, considerando sua condição histórica-social e ideológica e sua situação de produção, poderemos propiciar um trabalho de mudança do aporte teórico do sujeito-professor, fazendo intervir a história, preservando o caráter heteróclito e tenso da língua e comportando a ideologia como condição fundamental à produção de outro tipo de postura frente ao dizer.

Fundamentados nestes pressupostos, com o intuito de fortalecer nossos questionamentos sobre o ensino de produção textual, especificamente em materiais didáticos, analisaremos, na sequência, uma proposta textual do livro "Português", de Abaurre e Pontara (ensino médio - volume único, 1999), com o intuito de observar como se constituem aí - a partir da teoria e de sua prática - o texto e suas relações com o ensino-aprendizagem.

\section{O texto sob a observação da teoria e da prática}

A proposta textual escolhida encontra-se no livro didático "Português", de Abaurre e Pontara (ensino médio - volume único, 1999). Neste livro, as autoras entendem a linguagem como "uma atividade que modifica e constitui os interlocutores, e que é por eles constantemente modificada e manipulada" (MP, p.3), isto é, somente estudando-se a linguagem em relação ao uso efetivo que dela fazem os falantes, é que podem adquirir sentidos as discussões sobre língua, em todos os níveis de análise, além da metalinguagem necessária para a condução dessas discussões. Ancorado em tal visão de linguagem, os pressupostos pedagógicos deste livro didático baseiam-se na crença de que também o ensino de redação 
não se deve resumir a uma prática de produção de textos que se esgote em si mesma, ou seja, não bastam exercícios práticos e suas conseqüentes correções intuitivas para haver, segundo as autoras, "efetivamente o desenvolvimento de uma competência específica em leitura e produção de textos narrativos, expositivos e persuasivos” (MP,p.3). Para elas, é necessário discutir com os alunos, em aulas específicas de produção textual, os tópicos relevantes para a compreensão das características formais e de conteúdo referentes aos vários tipos de texto, de forma que os alunos possam levar esse conhecimento no momento da produção de seus próprios textos.

É devido a essa concepção que Abaurre e Pontara afirmam que não se parte do princípio de que basta "ser criativo" para escrever bem, a atividade de produção de textos, segundo elas, pressupõe o agenciamento de diversos recursos, conforme o projeto textual do autor, que, por isso, define-se como um todo em que os aspectos estipulados devem aparecer, ou seja, o texto é um todo composto de partes. As autoras (MP, p.8) ainda ressaltam que deve-se empregar na construção de um texto: mecanismos de coesão referencial; mecanismos de articulação frasal; recursos oferecidos pelo sistema verbal (emprego apropriado de tempos e modos verbais); recursos próprios do padrão escrito na organização textual (paragrafação, periodização, pontuação); convenções para citação de discurso alheio; ortografia oficial do Português, desconsiderando-se casos de idiossincrasia e palavras de freqüência muito restrita; regras de concordância verbal e nominal ${ }^{22}$.

No livro do aluno também são encontradas algumas observações teóricas sobre texto. No capítulo 3, intitulado: O Texto, as autoras esclarecem como o entendem.

O que é um texto? Um texto é uma manifestação lingüística produzida por alguém, em alguma situação concreta (contexto), com determinada intenção. (...) O que dá sentido a um texto é a combinação destes fatores: o lingüístico, o contextual e o intencional (...) Ele [texto] é sempre dirigido a alguém, ou seja, a situação de produção de um texto supõe a existência de um interlocutor a quem ele se dirige (...) O sentido dos textos é construído na interação entre o seu autor e o interlocutor a quem se destina. ${ }^{23}$

Nesta citação são apresentados, então, os três fatores preponderantes para a produção de textos na visão das autoras: o lingüístico - amplamente visto e esmiuçado no MP; o contexto - que, segundo Abaurre e Pontara, sem conhecê-lo se estará, muitas vezes, impossibilitado de compreender a intenção do autor ao produzir um texto; e a intenção - que é a mola propulsora da produção textual, é ela que determina o sentido e a forma de construção do texto. Observamos, ainda, uma visão um pouco reducionista em relação ao papel do interlocutor. Segundo as autoras ${ }^{24}$, o interlocutor de um texto é o leitor a quem este texto se dirige preferencialmente ou, em outras palavras, é o leitor em quem pensa o autor no momento da produção de um texto. Há, para cada texto, não só um contexto, mas também um interlocutor preferencial, ou seja, o interlocutor somente lê aquilo que o produtor quer lhe repassar, ele não tem qualquer papel de inter-relação ou interferência nesta concepção de produção textual. Vejamos como todas essas noções se ajustam na prática.

22 Observe-se que todos os fatores envolvidos na construção textual elencados pelas autores dizem respeito a estrutura da língua e ao padrão lingüístico, em nenhum momento se apresentam fatores relacionados ao sentido ou à relação socio-histórica dos textos.

23 ABAURRE, M.L. \& PONTARA, M.N. Português: volume único. São Paulo, Ed. Moderna, 1999.p.29

24 Ibidem. p. 30 
Proposta de Redação - 1

Agora, com base nas informações obtidas, transforme o relato lido em um texto narrativo. Procure caracterizar melhor as personagens, criar um cenário no qual se desenvolve a ação, apresentar motivos para os acontecimentos, enfim, elaborar de modo adequado os elementos necessários para a construção de um texto narrativo.

(ABAURRE \& PONTARA, 1999 - ensino médio - cap.3, p.36)

Torna-se necessário contextualizar a proposta. Ela segue a uma tarefa em que é apresentada a transcrição de um relato oral (uma moça relata uma troca de carros feita em uma festa) e é pedido para os alunos identificarem o acontecimento relatado, as circunstâncias em que se deu tal acontecimento e as personagens envolvidas nele. A partir desta tarefa, propõe-se a redação acima. Torna-se necessário, também, verificar o que as autoras compreendem por narração, já que se está pedindo, na proposta, para se transformar o relato em narrativa. Abaurre e Pontara apresentam a seguinte conceituação para os alunos:

A narrativa é um texto que pode ser definido como bem mais elaborado estruturalmente do que o relato, por um lado, e que, por outro, apresenta objetivos sensivelmente diferentes dos da crônica, sempre envolvida na análise do acontecimento contemporâneo. É bem verdade que nela também encontraremos fatos ou acontecimentos relatados. Ocorre, porém, que a principal preocupação de alguém que elabora um texto narrativo não está centrada nos fatos, mas sim na maneira como são apresentados. ${ }^{25}$

A partir dessa conceituação, fica-nos bem clara a visão distorcida que o livro didático apresenta sobre narração, ou seja, a forma de arranjo de significados em tipos textuais não interfere em nada no processo de compreensão dos textos, apenas determina os modos de enquadramento e formatação de cada texto. Portanto, a produção textual proposta acima não tem a função de trabalhar a linguagem como uma atividade que modifica e constitui os interlocutores e é por eles modificada e manipulada, como afirmado pelas autoras no MP, a proposta apenas serve para manipulação da linguagem, sem interesse pelo sentido, pela interlocução, nem ao menos pelo "desenvolvimento de uma competência específica em produção de textos" defendida pelas autoras e vista anteriormente, a não ser que esta competência esteja restrita à maneira como se deve apresentar os fatos em um texto. As concepções iniciais, apresentados no MP, sobre a descrença no ensino de redação como uma prática que se esgote em si mesma, é completamente esquecida no interior do material; se, na teoria, o sentido de um texto é construído no interação entre seu autor e o interlocutor a quem se dirige, na prática, o sentido nem mesmo tem relevância e, as concepções de autor e interlocutor são, ou apagadas, ou distorcidas. Na proposta de produção textual vista acima não é apresentado - nem implícita nem explicitamente - qualquer interlocutor; já o papel de autor, que, para Abaurre e Pontara, é aquele que "pressupõe o agenciamento de diversos recursos"(MP,p.3), é desempenhado pelas autoras do livro didático, pois são elas que apresentam um projeto textual, definem "as intenções", e estipulam os aspectos que devem aparecer. Dessa forma, o papel do aluno é o de fazer os arranjos e adequar à forma pedida o que lhe é apresentado, muito mais um exercício do que uma produção textual, essa proposta se mostra como mais uma forma encontrada, dentro deste capítulo, de se compreender/apreender a estrutura da narrativa. E para não termos dúvida disso, vejamos as instruções dadas a essa atividade no MP:

25 Ibidem. p.34 
Como a proposta solicita que o relato oral apresentado na abertura da unidade seja transformado em uma narrativa escrita, o professor precisa observar se os alunos vão se limitar a apresentar os acontecimentos ou se terão o cuidado de introduzir caracterizações de personagens, cenário, se farão uma melhor construção do tempo... Enfim, é preciso assegurar, no momento da correção, que o texto não se limite à apresentação do fato relatado, mas assuma as características estruturais de uma narrativa. (MP. p.22)[grifos nossos]

Reafirmando o que havíamos dito, não importa o que se vai escrever, mas o modo como escrevê-lo. As instruções deixam claro que a apresentação do fato relatado é uma limitação do texto, o que se requer é a inserção dos elementos narrativos e sua estruturação característica. Como no relato apresentado não há referências às características básicas da narrativa como cenário, caracterização de personagens, espaço etc., o aluno terá que "criar" tudo isso, para dessa forma adequar-se ao que é proposto. Contudo, lembremos de uma afirmação das autoras feita no início desta análise: "não se parte do princípio de que basta 'ser criativo' para escrever bem." (MP, p.3). Quer dizer, na teoria a criatividade não é uma característica importante, mas na prática ela se torna essencial. Infelizmente, esta proposta revela o que observamos em nossa dissertação, que é a dissonância, nos materiais didáticos, entre teoria e prática.

\section{Conclusão}

A distância e mesmo a contradição ente teoria e prática observadas nos livros didáticos, dos quais trouxemos apenas um exemplo, mas que se repete indefinidamente, é inquietante. Mesmo quando não existe uma proclamação teórica determinada ou definida nos matérias didáticos, percebe-se, através de seus objetivos, que a teoria parece um discurso mouco, uma fachada ilusionista que apresenta algo que não irá se concretizar no interior do livro. Na prática de produção textual, o que se encontra, mesmo, é a desculpa para uma reflexão sobre um ponto complexo da teoria gramatical, ou um momento para exercitar determinado aspecto textual, ou ainda, um simples cumprir função dentro do capítulo, alienado a tudo que se tenha estudado, procurando "instigar a criatividade ou a socialização". Observamos que a transformação do texto no objeto e objetivo principal das aulas de língua somente fez, no livro didático, com que se mudassem as formas materiais (da frase para o texto) de aplicação dos mesmos conteúdos - sintáticos, morfológicos, estruturais. Aplicam-se, agora, aos textos, os mesmos exercícios e as mesmas exigências que se aplicavam à frase; e isto é um sinal claro de que a simples elucubração da significatividade do texto como único objeto real de ensino de língua não exerce maiores modificações na forma normativa de ensino que se tem visto até então. Requerer mudanças não significa somente mudança de objeto, mas mudança de hábitos metodológicos, de posturas pedagógicas e, principalmente, mudanças na forma de constituir teoria e prática.

Referências

ABAURRE, M.L. \& PONTARA, M.N. Português: volume único. São Paulo, Ed. Moderna, 1999.

COURTINE, Jean-Jacques. Quelques problèmes théoriques et métthodologiques en analyse du Discours; à propos du discourse communiste adressé aux chrétiens. Langages, (62): 9-127. Paris, juin, 1981. 


\section{Conexão Letras}

INDURSKY, Freda. Da heterogeneidade do discurso à heterogeneidade do texto e suas implicações no processo de leitura. In: ERNEST-PEREUS, A. \& FUNCK, S. (orgs.) A leitura e a escrita como práticas discursivas. São Paulo, Educat, 2001.

ORLANDI, Eni P. A linguagem e seu funcionamento: as formas do discurso. Campinas, Ed. Pontes, 1983.

Discurso e Texto: formação e circulação de sentidos. Campinas, Ed. Pontes, 2001. PÊCHEUX, Michel. Semântica e discurso: uma crítica à afirmação do óbvio. (1975). Trad. bras. 1988 - $3^{\mathrm{a}}$ ed. Campinas, Editora da UNICAMP, 1997. 